\title{
Failure of cerebrospinal fluid homovanillic acid to predict levodopa response in Parkinson's disease
}

\author{
WILLIAM J. WEINER AND HAROLD L. KLAWANS, JR. \\ From the Department of Neurological Sciences, Rush-Presbyterian-St. Luke's Medical Center, \\ Chicago, Illinois 60612, U.S.A.
}

SUMMARY Lumbar cerebrospinal fluid homovanillic acid levels were estimated in 60 patients with Parkinsonism before and during levodopa treatment. There was a slight negative correlation between pretreatment CSF homovanillic acid levels and disability. There was no correlation between pretreatment homovanillic acid levels and clinical response to levodopa. Patients with high pretreatment levels did as well as those with depressed levels. High (normal or near normal) levels of CSF homovanillic acid in a patient with Parkinsonism do not necessarily indicate that the Parkinsonism will not respond to levodopa. These patients should receive the benefit of a trial of levodopa. There was also no correlation between homovanillic acid level during treatment and improvement. Patients with minimal increases in CSF homovanillic acid responded as well as those with greater elevations. Failure of levodopa to increase CSF homovanillic acid significantly does not indicate that the patient will not respond to levodopa and that levodopa should be discontinued. Other factors, such as vitamin $B_{6}$ consumption, should be investigated.

It is now well known that Parkinson's disease is associated with a decreased concentration of dopamine within the striatum (Hornykiewicz, 1966). It is equally well established that the concentration of homovanillic acid, the major catabolic product of dopamine metabolism, is also decreased in the cerebrospinal fluid (CSF) of patients with Parkinson's disease (Johansson and Roos, 1967). The effectiveness of levodopa therapy in Parkinson's disease has resulted in numerous attempts to understand the neuropharmacological changes involved. A number of investigators have analysed the CSF for the catabolic products of dopamine. It was demonstrated that chronic oral levodopa therapy elevated the CSF homovanillic acid concentration but that the raised level had no quantitative relationship to improvement in the symptoms of Parkinsonism (Weiner, Harrison, and Klawans, 1969; Curzon, Godwin-Austen, Tomlinson, and Kantamaneni, 1970). Recently there have been several reports concerning homovanillic acid in CSF which have cast doubt on the earlier conclusion and that have implied that there is a definite correlation between increasing CSF homovanillic acid concentration and improvement in Parkinson's disease (Godwin-Austen, Kantamaneni, and Curzon, 1971; Hinterberger and Andrews, 1972). It has also been proposed on the basis of the initial cerebrospinal fluid homovanillic acid concentration in patients with Parkinson's disease that it is possible to differentiate two populations of patients: one population that will respond to L-dopa and one population that will not (Jéquier and Dufresne, 1972). The present study was undertaken to determine in a large series of patients whether alterations in CSF homovanillic acid were correlated with improvement in the disease state and to determine whether there is any prognostic value to the initial concentration of homovanillic acid in the cerebrospinal fluid.

\section{METHODS}

Sixty patients with Parkinson's disease were evaluated clinically and given a rating score on the Northwestern disability scale (Canter, de la Torre, and Mier, 1961). This consists of five separate scales, each of which pertains to one type of activity (walk747 
speech). Each activity is rated from 0 (normal) to 10 (total disability). Before beginning therapy with levodopa a lumbar puncture was performed and the CSF was analysed for homovanillic acid. The patients were started on gradually increasing doses of levodopa until a satisfactory result was obtained, which initially was in the range of 3-4 g daily. At the end of two to four weeks of observation a second clinical interview with assessment of the Northwestern University scale rating was obtained. A second lumbar puncture was performed and the CSF again analysed for homovanillic acid.

The samples of CSF were simultaneously analysed by the fluorometric method of Anden, Roos, and Werdinius (1963). A modification in this method was the use of ethylacetate (Sharman, 1963) to extract the homovanillic acid from salt saturated aliquots. An Aminco-Bowman spectrophotofluorometer was used for the fluorescent measurements. The linearity of the standard curve was established with duplicate assays of authentic homovanillic acid standards. The correlation between CSF homovanillic acid concentration calculated by the use of the standard curve and by the use of internal standard fluorescent response were within the same order of magnitude. The fluorescent product from CSF was found to be identical with homovanillic acid on the basis of its emission and excitation spectra. Average recovery of internal standard was $62.5 \%$.

\section{RESULTS}

Table 1 shows each patient's percent improvement score on the Northwestern disability scale as well as the pretreatment and during-treatment CSF homovanillic acid conientration in $\mathrm{ng} / \mathrm{ml}$. The table is further subdivided into 17 patients who demonstrated more than $40 \%$ improvement during this period and 43 patients who demonstrated less than $40 \%$ improvement. Percent improvement is defined by Klawans and Garvin (1969) as (initial disability-final disability/ initial disability) $\times 100$. Percent improvement was used instead of absolute improvement because we feel that it gives a clearer picture of clinical response in terms of drug-induced changes in the patient's ability to carry out the various activities measured. Absolute improvement of a given degree means much less the more marked the initial disability. Percent improvement describes the relative change in the patient's behaviour for any level of initial disability. The average CSF homovanillic acid for those 17 patients attaining greater than $40 \%$
TABLE 1

PERCENT IMPROVEMENT IN PARKINSON'S DISEASE AND HOMOVANILLIC ACID CONCENTRATION BEFORE AND DURING TREATMENT WITH LEVODOPA

\begin{tabular}{|c|c|c|c|}
\hline $\begin{array}{l}\text { Case } \\
\text { (no.) }\end{array}$ & $\begin{array}{c}\text { Improvement on } \\
\text { Northwestern } \\
\text { disability scale } \\
(\%)\end{array}$ & $\begin{array}{c}\text { Initial pretreatment } \\
\text { CSF homovanillic } \\
\text { acid concentration } \\
(n g / m l .)\end{array}$ & $\begin{array}{c}\text { During-treatment } \\
\text { CSF homovanillic } \\
\text { acid concentration } \\
(n g / m l .)\end{array}$ \\
\hline
\end{tabular}

A. Patients with a greater than $40 \%$ response to levodopa

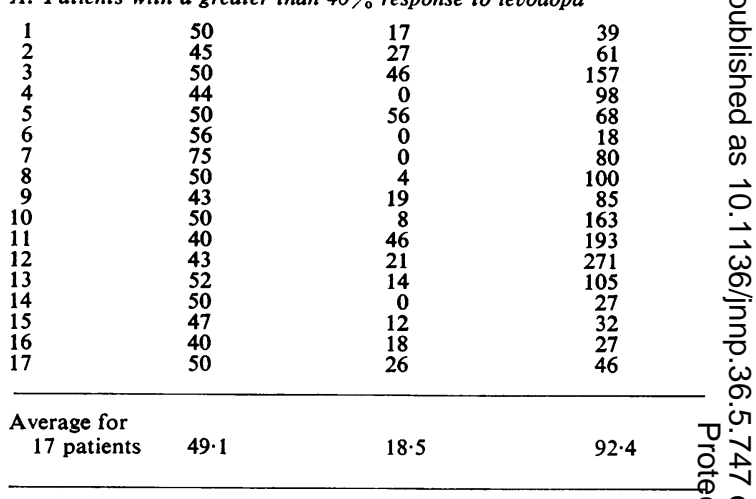

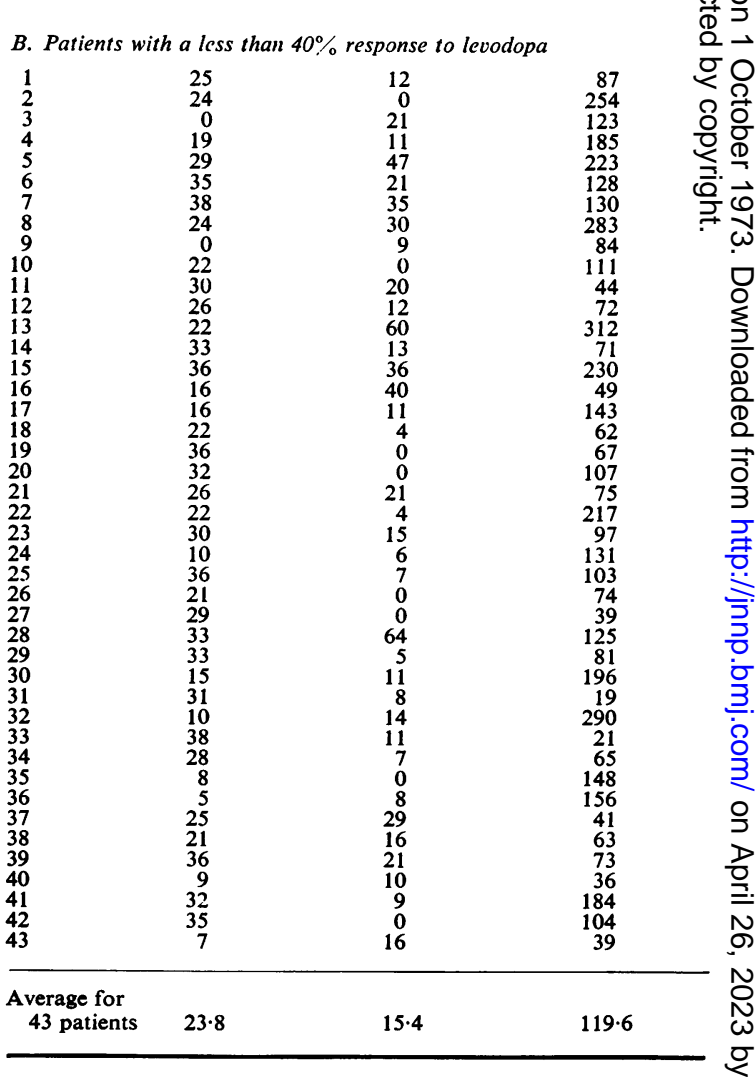




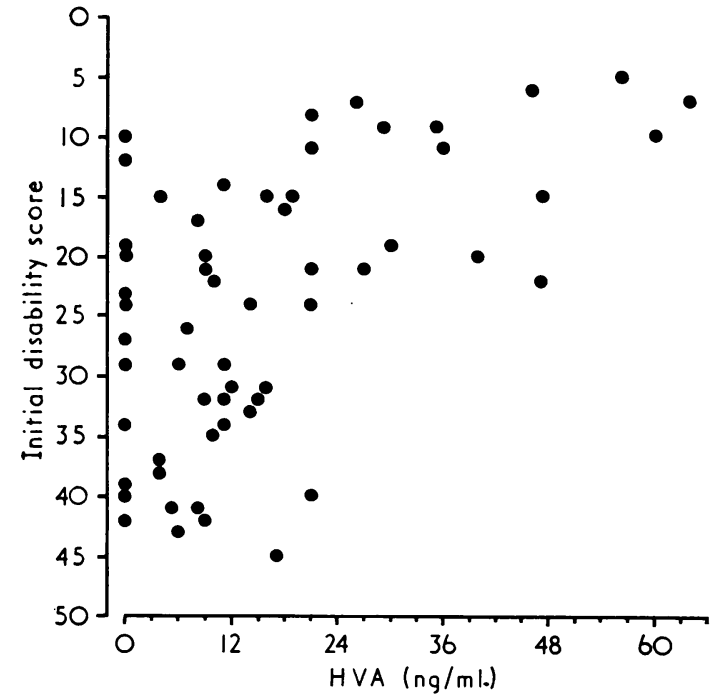

FIG. 1. Relationships between control raw Northwestern disability score and initial cerebrospinal fluid homovanillic acid concentration expressed in $\mathrm{ng} / \mathrm{ml}$.

TABLE 2

PERCENT IMPROVEMENT IN PARKINSON'S DISEASE AND HOMOVANILLIC ACID CONCENTRATION BEFORE AND DURING TREATMENT WITH LEVODOPA IN PATIENTS SHOWING LESS THAN $10 \%$ IMPROVEMENT

\begin{tabular}{lccc}
\hline $\begin{array}{l}\text { Case } \\
\text { no. }\end{array}$ & $\begin{array}{c}\text { Improvement on } \\
\text { Northwestern } \\
\text { disability scale } \\
(\%)\end{array}$ & $\begin{array}{c}\text { Initial pretreatment } \\
\text { CSF homovanillic } \\
\text { acid concentration } \\
(\text { ng/ml. })\end{array}$ & $\begin{array}{c}\text { During-treatment } \\
\text { CSF homovanillic } \\
\text { acid concentration } \\
(\text { ng/ml. })\end{array}$ \\
\hline 1 & 0 & 21 & 123 \\
2 & 0 & 9 & 84 \\
3 & 10 & 6 & 131 \\
4 & 10 & 4 & 290 \\
5 & 8 & 8 & 148 \\
6 & 5 & 10 & 156 \\
7 & 9 & 16 & 36 \\
8 & 7 & & 39 \\
\hline
\end{tabular}

response was $18.5 \mathrm{ng} / \mathrm{ml}$, while in those 43 patients in whom the response to levodopa was less than $40 \%$ the average CSF fluid homovanillic acid was $15.4 \mathrm{ng} / \mathrm{ml}$. There was no statistical difference in these values within the method of analysis employed for CSF homovanillic acid.

Table 2 represents eight patients abstracted from our patient population in whom the improvement on levodopa was $10 \%$ or less
TABLE 3

AVERAGE CONCENTRATION OF CEREBROSPINAL FLUID HOMOVANILLIC ACID (NG/ML.) FOR EACH GROUP OF PARKINSONISM PATIENTS

\begin{tabular}{|c|c|c|c|}
\hline $\begin{array}{l}\text { Patients } \\
\text { (no.) }\end{array}$ & $\begin{array}{c}\text { Average } \\
\text { initial } \\
\text { pretreatment } C S F \\
\text { homovanillic } \\
\text { acid } \\
\text { concentration } \\
(\mathrm{ng} / \mathrm{ml} .)\end{array}$ & $\begin{array}{c}\text { During- } \\
\text { treatment } \\
C S F \\
\text { homovanillic } \\
\text { acid } \\
\text { concentration } \\
(n g / m l .)\end{array}$ & $\begin{array}{c}\text { Average } \\
\text { improvement } \\
\text { on } \\
\text { Northwestern } \\
\text { disability } \\
\text { scale } \\
(\%)\end{array}$ \\
\hline $\begin{aligned} & 40 \% \\
& 17\end{aligned}$ & $15 \cdot 4$ & $92 \cdot 4$ & $49 \cdot 1$ \\
\hline $\begin{array}{l}<40 \% \text { improvement } \\
43\end{array}$ & $18 \cdot 4$ & $114 \cdot 4$ & $24 \cdot 6$ \\
\hline $\begin{array}{l}<10 \% \text { improvement } \\
\quad 8\end{array}$ & $10 \cdot 5$ & 125.9 & $6 \cdot 1$ \\
\hline All patients & & & $31 \cdot 5$ \\
\hline
\end{tabular}

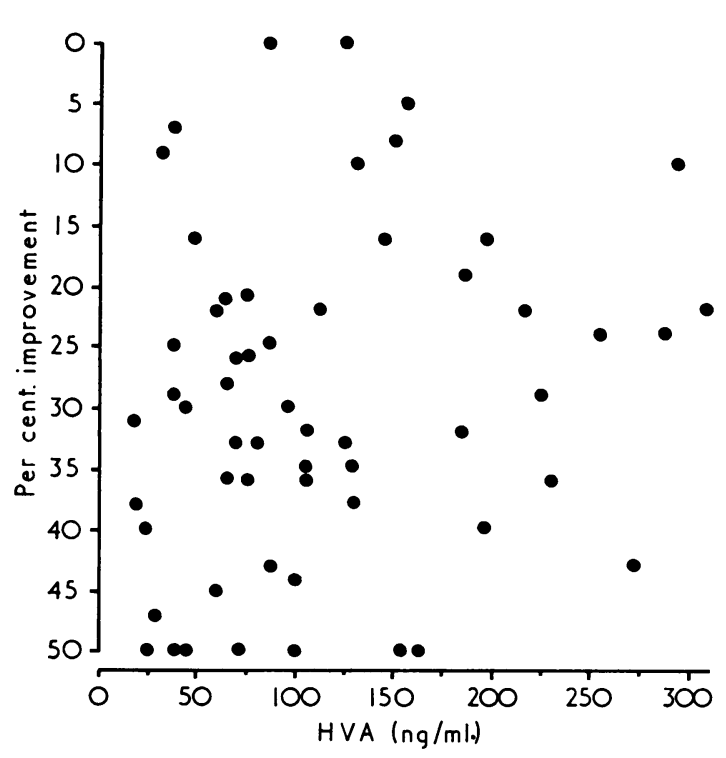

FIG. 2. Relationship between percent improvement on Northwestern disability scale and during-treatment cerebrospinal fluid homovanillic acid expressed in $n g / m l$.

according to their evaluation by the Northwestern disability scale. This group of patients was isolated because of their very poor initial response to therapy. Their average CSF homovanillic acid level was obtained. The value of 
$10.5 \mathrm{ng} / \mathrm{ml}$. was lower than the average concentration of $18.5 \mathrm{ng} / \mathrm{ml}$. for patients who improved more than $40 \%$. There is no significant difference between these two values.

Table 2 also indicates that, despite the fact that there was little or no improvement in this group's disability scores, there was always an increase in the concentration of CSF homovanillic acid provided the patients were given longterm levodopa therapy. Table 3 shows the average CSF homovanillic acid concentration before and during treatment with levodopa for all groups of patients with Parkinsonism.

In Fig. 1 the initial CSF homovanillic acid concentration is correlated with the initial raw score on the Northwestern disability scale. Although it can be seen that there is no direct linear relationship in these two variables, there is certainly a suggestion of a relationship. In a crude fashion it appears that the higher the initial disability of the patient the lower the initial CSF homovanillic acid concentration. It is obvious that this is a generalization and that for a given patient this relationship might not be at all true.

Figure 2 represents the relationship between percent improvement on the disability scale rating and CSF homovanillic acid concentration during L-dopa therapy. There is no relationship between these two variables.

\section{DISCUSSION}

The finding of a possible relationship between low levels of cerebrospinal fluid homovanillic acid in the pretreatment stage and increased disability rating is of interest. Homovanillic acid is the final product of dopamine catabolism and the major catabolic product of dopamine. Only small amounts of homovanillic acid penetrate from the plasma into the spinal fluid, and the spinal fluid concentration of homovanillic acid is felt to reflect the turnover of dopamine within the brain (Bartholini, Pletscher, and Tissot, 1966). The brains of all patients who have died with Parkinson's disease, which have had the appropriate chemical analyses performed, have revealed decreased striatal dopamine (Ehringer and Hornykiewicz, 1960). The pathology of Parkinson's disease is a degenerative process involving the dopaminergic-rich nigrostriatal neuronal system. It might be reasonable, therefore, to assume that in Parkinson's disease as the degenerative process continues the striatal dopamine concentration falls. When the striatal dopamine concentration decreases, the turnover of dopamine is decreased and subsequently the concentration of CSF homovanillic acid is decreased. In a large series of patients, Rinne and Sonninen (1972) have also found a similar negative correlation between lumbar CSF homovanillic acid level and severity of disease $\frac{\bar{m}}{\bar{m}}$ and disability. Our results and those of Rinne $\stackrel{\mathbb{Q}}{\varrho}$ and Sonninen suggest that lower CSF homo- ळ vanillic acid levels are related to greater degrees $\overrightarrow{0}$ of disability from Parkinsonism, probably as a reflection of decreased turnover of striatal $\vec{\omega}$ dopamine.

There was no significant correlation between lumbar CSF homovanillic acid and age in our $\omega_{\mathrm{o}}$ patients. This is similar to the results of Guldberg, Ashcroft, and Turner (1969) and Rinne $\stackrel{ }{f}$ and Sonninen (1972). Bowers (1972) has pointed out that, although CSF homovanillic acid tendis to increase in older age groups, age is a factor clinical studies only if there is a marked dis-s? crepancy in ages between groups being studie $\$$ Age does not appear to be a factor in the study of Parkinsonism, which today is primarily disease of the older population.

In a series of 14 patients, Hinterberger and Andrews (1972) reported that improvement of symptoms of Parkinsonism was correlated with increased concentrations of CSF homovanillic $\stackrel{\otimes}{\varnothing}$ acid. However, we have presented evidence in $60 \propto$ patients that there is no definite correlation $\overrightarrow{\overrightarrow{0}}$ between percent improvement in Parkinsonism and the elevation in CSF homovanillic acid. Hinterberger and Andrews (1972) suggest that in a patient with Parkinson's disease who is not? responding well to therapy an assessment of $\mathrm{CSF}^{\circ}$ homovanillic acid may be of prognostic value as 3 . to future response. This was based upon the observation that two patients receiving $\mathrm{L}$-dopa showed no clinical improvement and no increase in lumbar CSF homovanillic acid concentration. $>$ These authors suggest that levodopa should be을. discontinued in a patient with no response to N levodopa and no measurable increase in $\mathrm{CSF}_{\mathrm{N}}$ homovanillic acid. It is of interest to note that in our Table 2 all eight patients with little or no 
response to levodopa are seen to have increased CSF homovanillic acid. This lack of correlation between lack of clinical response and elevation of CSF homovanillic acid has been noted previously (Weiner et al., 1969; Curzon et al., 1970). In controlled circumstances, where it is certain that the patient is receiving and taking the medication, the only time we have observed the failure of CSF homovanillic acid to increase while on levodopa was in a single patient who inadvertently was receiving vitamin $B_{6}$ simultaneously (Klawans, 1971a). After vitamin $B_{6}$ was discontinued the patient had a good clinical response to levodopa and an elevation in CSF homovanillic acid level.

The failure of CSF homovanillic acid to increase while on long-term levodopa therapy is difficult to understand. The possibility that the patient is inadvertently receiving vitamin $B_{6}$ or that he is not really taking his medication must always be considered. It is now known that nowhere near all of the homovanillic acid found in the cerebrospinal fluid after levodopa is related to dopamine metabolism. A significant percentage of the measurable homovanillic acid is actually formed within the walls of the cerebral capillaries from circulating L-dopa (Falck et al., 1962). Levodopa therapy should result in elevated circulating levodopa levels and increased CSF homovanillic acid levels in all patients unless there is increased peripheral metabolism, due perhaps to excess vitamin $B_{6}$ (Klawans, 1971a) or possibly poor absorption of levodopa.

It is our contention that the CSF homovanillic acid concentration should not be regarded as a reliable indication of whether or not to continue therapy in the poorly responding patient. There is no correlation between CSF homovanillic acid concentration, chronic levodopa therapy, and clinical status. Three patients (A16, B16, and B33) had an increase in CSF homovanillic acid of $10 \mathrm{ng} / \mathrm{ml}$. or less. The increase in CSF homovanillic acid in these three patients respectively was 9,9 , and $10 \mathrm{ng} / \mathrm{ml}$. The percentage improvement in these patients respectively was 40,16 , and $38 \%$. This is an average improvement of $28 \%$, which is not significantly different from the average improvement of all 60 patients $(31 \cdot 5 \%)$. Clinical experience with chronic levodopa therapy has demonstrated that in some patients three to six months of therapy is required before significant improvement is seen.

Another recent suggestion by Jéquier and Dufresne (1972) that patients with Parkinsonism can be divided into two prognostic populations based on the initial CSF homovanillic acid concentration needs further investigation. These authors suggest that there is one population of patients with low CSF homovanillic acid who respond better to levodopa treatment and that a second group of patients with normal CSF homovanillic acid do not respond to levodopa. We have found no evidence to support these postulates. In 17 patients whose initial response was greater than $40 \%$ improvement while on levodopa therapy, the average CSF homovanillic acid was $18.5 \mathrm{ng} / \mathrm{ml}$., while in 43 patients with less than $40 \%$ improvement while on levodopa therapy the average CSF homovanillic acid was $15.4 \mathrm{ng} / \mathrm{ml}$. The five patients with the highest levels of homovanillic acid were also examined closely in this regard. If there is a subgroup of patients with Parkinsonism with normal or near normal CSF homovanillic acid levels who do not respond to levodopa, they should be found among these patients. The five patients B28, B13, A5, B5, and A3 had homovanillic acid levels respectively of $64,60,56,47$, and $46 \mathrm{ng} / \mathrm{ml}$. The mean CSF fluid homovanillic acid of these five patients was $54.6 \mathrm{ng} / \mathrm{ml}$, as opposed to $16 \cdot 3$ $\mathrm{ng} / \mathrm{ml}$. for the entire group and $66 \mathrm{ng} / \mathrm{ml}$. for normal individuals (Klawans, 1971b). The percent improvement in these five individuals respectively was $33 \%, 22 \%, 50 \%, 29 \%$, and $50 \%$. This is an average improvement of $36.8 \%$ as opposed to $31.5 \%$ for the entire group. All of these patients showed significant improvement while on levodopa. This does not prove that there is not a subgroup of individuals with manifestations of Parkinsonism, normal dopamine metabolism as estimated by CSF homovanillic acid levels, and poor response to levodopa. It does suggest, however, that not all Parkinsonism patients with normal or near normal CSF homovanillic acid are part of such a subgroup and incapable of improving on longterm levodopa therapy.

The conclusion of Jéquier and Dufresne (1972) was based upon an analysis of ventricular fluid, while ours is based upon cerebrospinal fluid analysis. Homovanillic acid levels are much 
higher in the ventricular fluid than in spinal fluid in patients with and without Parkinsonism. (Guldberg, Ashcroft, Turner, and Hanieh, 1968) as well as in normal dogs (Guldberg et al., 1966). Guldberg et al. (1968) feel that the concentration gradient for homovanillic acid in the spinal fluid is related to active removal of homovanillic acid as it passes down from the lateral ventricles, especially in the region of the fourth ventricle. This raises the possibility that ventricular homovanillic acid level is a more sensitive measure of dopamine turnover in the adjacent structures (striatum) than lumbar cerebrospinal fluid levels. This may account for the difference between our findings and those of Jéquier and Dufresne (1972) and also explain why other investigators examining CSF for homovanillic acid have not drawn attention to the subgroup described by Jéquier and Dufresne.

It is concluded that the initial pretreatment CSF homovanillic acid concentration may have a rough correlation to degree of disability. However, no evidence to support the concept of correlation between improvement and alterations in CSF homovanillic acid concentrations was found, nor was there any support for proposing that the initial CSF homovanillic acid is of prognostic value in determining response to levodopa therapy.

\section{REFERENCES}

Anden, N. E., Roos, B. E., and Werdinius, B. (1963). On the occurrence of homovanillic acid in brain and cerebrospinal fluid and its determination by a fluorometric method. Life Sciences, No. 7, 448-458.

Bartholini, G., Pletscher, A., and Tissot, R. (1966). On the origin of homovanillic acid in the cerebrospinal fluid. Experientia, 22, 609-610.

Bowers, M. B., Jr. (1972). Clinical measurements of central dopamine and 5-hydroxytryptamine metabolism. Neuropharmacology, 11, 101-111.

Canter, G. J., de la Torre, R., and Mier, M. (1961). A method for evaluating disability in patients with Parkinson's disease. Journal of Nervous and Mental Disease, 133, 143-147.
Curzon, G., Godwin-Austen, R. B., Tomlinson, E. B., and Kantamaneni, B. D. (1970). The cerebrospinal fluid homovanillic acid concentration in patients with Parkinsonism treated with L-dopa. Journal of Neurology, Neurosurgery, and Psychiatry, 33, 1-6.

Ehringer, H., and Hornykiewicz, O. (1960). Verteilung von Noradrenalin und Dopamin (3-Hydroxytyramin) im Gehirn des Menschen und ihr Verhalten bei Erkrankungen des extrapyramidalen Systems. Klinische Wochenschrift, 38, 1236-1239.

Godwin-Austen, R. B., Kantamaneni, B. D., and Curzon, G. (1971). Comparison of benefit from L-dopa in Parkinsonism with increase of amine metabolites in the CSF. Journal of Neurology, Neurosurgery, and Psychiatry, 34, 219-223.

Guldberg, H. C., Ashcroft, G. W., Turner, J. W., and Hanieh, A. (1968). The use of cerebrospinal fluid in the study of dopamine and 5-hydroxytryptamine metabolism in parkinsonism. In Third Symposiumon Parkinson's Disease, Edinburgh, 1968. Pp. 50-54. Livingstone: Edinburgh.

Guldberg, H. C., Ashcroft, G. W., and Crawford, T. B. B. C (1966). Concentrations of 5-hydroxyindolylacetic acid and homovanillic acid in the cerebrospinal fluid of the dog before and during treatment with probenecid. Life Sciences, 5, 1571-1575.

Hinterberger, H., and Andrews, C. J. (1972). Catecholamine metabolism during oral administration of levodopa. Archives of Neurology (Chicago), 26, 245-252.

Hornykiewicz, O. (1966). Dopamine (3-hydroxytyraminep and brain function. Pharmacological Review, 18, 925-964

Jéquier, E., and Dufresne, J.-J. (1972). Biochemical investigß tion in patients with Parkinson's disease treated witc L-dopa. Neurology (Minneap.), 22, 15-22.

Johansson, B., and Roos, B.-E. (1967). 5-hydroxyindoleacet and homovanillic acid levels in the cerebrospinal fluid of healthy volunteers and patients with Parkinson's syndromg Life Sciences, 6, Part 1, 1449-1454.

Klawans, H. L., Jr. (1971a). Effect of vitamin $B_{6}$ on levodop induced changes in spinal fluid homovanillic acid. Journ of Neurological Sciences, 14, 421-426.

Klawans, H. L., Jr. (1971b). Cerebrospinal fluid homovanillic acid in Huntington's chorea. Journal of Neurological Sciences, 13, 277-279.

Klawans, H. L., Jr., and Garvin, J. S. (1969). Treatment of parkinsonism with L-dopa. (Study of 105 patients). Diseases of the Nervous System, 30, 737-746.

Rinne, U. K., and Sonninen, V. (1972). Acid monoamine metabolites in the cerebrospinal fluid of patients with Parkinson's disease. Neurology (Minneap.), 22, 62-67.

Sharman, D. F. (1963). A fluorimetric method for the estimation of 4-hydroxy-3-methoxyphenylacetic acid (homovanillic acid) and its identification in brain tissue. British Journal of Pharmacology, 20, 204-213.

Weiner, W. J., Harrison, W. H., and Klawans, H. L., Jr. (1969). L-dopa and cerebrospinal fluid homovanillic acid in parkinsonism. Life Sciences, 8, Part 1, 971-976. 